DOI: 10.20472/IAC.2018.044.030

\title{
KOLENTINO MPETA
}

North West University, South Africa

NTEBO MOROKE

North West University, South Africa

LESEGO GABAITIRI

University of Botswana, Botswana

\section{A TEST OF THE APPLICABILITY OF THE THEORY OF PLANNED BEHAVIOUR IN THE BOTSWANA CONTEXT USING MULTIPLE REGRESSION}

\begin{abstract}
:
Culturally sensitive and effective interventions to reduce the high risky sexual behaviours remain one promising approach to easing the effects of HIV and AIDS on African adolescents.

In order to test the applicability of the theory of planned behaviour (TPB) in preventing HIV and AIDS among adolescents within the Botswana context, multiple regression modelling was applied to baseline data from a randomised control trial involving about 800 Batswana in-school adolescents. The predictors of interest were all derived from the TPB. The results indicated that there was significant correlation $(p<0.01)$ between all the variables. Furthermore, the results revealed that the TPB predictors, apart from affective attitude, were predictive of condom use intention among Batswana adolescents. The regression model was significant $(F(4,789)=159.763, p<0.001)$ and the factors explained $44.5 \%$ of the variation in the model.
\end{abstract}

\section{Keywords:}

HIV and AIDS, Theory of planned behaviour, multiple regression

JEL Classification: C10 